\section{Insights on cancer resistance in vertebrates: reptiles as a parallel system to mammals}

\author{
Ylenia Chiari (D), Scott Glaberman (1D) and Vincent J. Lynch
}

The Opinion article, 'Mechanisms of cancer resistance in long-lived mammals' (Nat. Rev. Cancer. https://doi.org/10.1038/s41568-0180004-9 (2018) $)^{1}$, highlights how long-lived and large-bodied organisms are a natural resource for investigating the molecular mechanisms that underlie non-transmissible cancer resistance and increased tumour suppression in mammals. Although there are evolutionary advantages to long life spans and large body sizes ${ }^{2,3}$, there is also greater risk of accumulating genotoxic and cytotoxic damage as a consequence of living longer and having more cells. Thus, long-lived and large-bodied organisms are theoretically at an increased risk of genomic instability and cancer ${ }^{4}$. Consistent with this increased risk, there is a strong positive correlation between body size and cancer incidence within species such as $\operatorname{dogs}^{5}$ and humans ${ }^{6}$. Evidently, however, long-lived and largebodied organisms do exist - thus they likely have evolved mechanisms for reducing their risk of developing cancer ${ }^{1,7-9}$.

The ideal study system in which to explore these questions is one in which a long-lived, large-bodied lineage is phylogenetically deeply nested within a clade with normal life spans and body sizes. Thus far, most studies on the evolution of augmented cancer resistance have focused on mammals such as long-lived naked molerats $^{1}$ and large-bodied elephants ${ }^{10}$. While mammals are without a doubt an excellent model system, reptiles also pose numerous advantages for studying cancer resistance because of their huge diversity in longevity, body size ${ }^{11}$, ecology, habitat type, physiology and metabolic rates - all factors influencing mechanisms of cancer protection and tumour repression ${ }^{1,4}$. These factors also vary with respect to environmental temperature ${ }^{12}$, a concern considering current climate change. Even within closely related species, reptiles also exhibit large differences in body size, resting metabolic rate and longevity. For example, giant Galápagos tortoises can weigh up to 100 times more and live 3-5 times longer than their closest living relative, the Chaco tortoise, from which they diverged around 3-4 million years ago $^{13}$. The presence of larger, longlived species that are nested deeply within clades with much smaller, shorter-lived species permits the use of evolutionary comparative genomics approaches to discern potentially causal molecular and genetic changes associated with cancer protection and tumour suppression from other unrelated differences among species. We therefore suggest that reptiles are an ideal parallel system to mammals in which to gain a more comprehensive understanding of the ecological, molecular and evolutionary influences on cancer susceptibility or resistance. While data on mechanisms of cancer protection, tumour suppression and incidence of benign and malignant cancer are accumulating mostly for mammals and more recently for birds ${ }^{9}$, other vertebrates have not been similarly investigated. Specifically, although cancer occurrence has been recorded in reptiles ${ }^{14}$, comparative prevalence data on cancer across reptiles with different life spans and body sizes are currently lacking. This overall lack of comparative oncological data, including incidence of cancer, cancer type and mortality rates, on diverse animals currently represents an important gap toward understanding cancer susceptibility and protection ${ }^{4,14,15}$.
Ylenia Chiari (D) ${ }^{1 *}$, Scott Glaberman (D) ${ }^{\prime}$ and Vincent J. Lynch ${ }^{2}$ 'University of South Alabama, Department of Biology, Mobile, AL, USA.

${ }^{2}$ University of Chicago, Department of Human Genetics \& Department of Organismal Biology \& Anatomy, Chicago, IL, USA. *e-mail: yleniachiari@southalabama.edu https://doi.org/10.1038/s41568-018-0033-4

1. Seluanov, A., Gladyshev, V. N., Vijg, J. \& Gorbunova, V. Mechanisms of cancer resistance in long-lived mammals. Nat. Rev. Cancer https://doi.org/10.1038/ s41568-018-0004-9 (2018)

2. Blanckenhorn, W. U. The evolution of body size: what keeps organisms small? Q. Rev. Biol. 75, 385-407 (2000).

3. Hone, D. W. E. \& Benton, M. J. The evolution of large size: how does Cope's rule work? Trends Ecol. Evol. 20 4-6 (2005).

4. Harris, V. K., Schiffman, J. D. \& Boddy, A. M. in Ecology and Evolution of Cancer (eds Ujvari, B., Roche, B. \& Thomas, F.) 99-110 (Academic Press, 2017).

5. Dobson, J. M. Breed-predispositions to cancer in pedigree dogs. ISRN Vet. Sci. 2013, 941275 (2013).

6. Green, J. et al. Height and cancer incidence in the Million Women Study: prospective cohort, and meta-analysis of prospective studies of height and total cancer risk. Lancet Oncol.12, 785-794 (2011).

7. Peto, R., Roe, F. J., Lee, P. N., Levy, L. \& Clack, J. Cancer and ageing in mice and men. Br. J. Cancer 32 411-426 (1975)

8. Leroi, A. M., Koufopanou, V. \& Burt, A. Cancer selection. Nat. Rev. Cancer 3, 226-231 (2003).

9. Møller, A. P., Erritzøe, J. \& Soler, J. J. Life history, immunity, Peto's paradox and tumours in birds. J. Evol. Biol. 30, 960-967 (2017).

10. Sulak, M. et al. TP53 copy number expansion is associated with the evolution of increased body size and an enhanced DNA damage response in elephants. elife 5, e11994 (2016).

11. Allen, W. L., Street, S. E. \& Capellini, I. Fast life history traits promote invasion success in amphibians and reptiles. Ecol. Lett. 20, 222-230 (2017).

12. White, C. R., Phillips, N. F. \& Seymour, R. S. The scaling and temperature dependence of vertebrate metabolism. Biol. Lett. 2, 125-127 (2006).

13. Poulakakis, N., Russello, M., Geist, D. \& Caccone, A Unravelling the peculiarities of island life: vicariance, dispersal and the diversification of the extinct and extant giant Galápagos tortoises. Mol. Ecol. 21 , 160-173 (2012).

14. Madsen, T. et al. in Ecology and Evolution of Cancer (eds Ujvari, B., Roche, B. \& Thomas, F.) 11-46 (Academic Press, 2017).

15. Roche, B., Møller, A. P., DeGregori, J. \& Thomas, F. in Ecology and Evolution of Cancer (eds Ujvari, B., Roche, B. \& Thomas, F.) 181-191 (Academic Press, 2017).

Acknowledgements

The authors are thankful to Isabella Capellini for sharing the dataset on life history traits in reptiles published in REF."1.

\section{Author contributions}

Y.C. researched the data for the article. S.G. and V.J.L. contributed substantially to discussion of the article's content. Y.C., S.G. and V.J.L. contributed equally to writing the article and reviewing and editing the article before submission.

Competing interests

The authors declare no competing interests. 